\title{
Marek's Disease Virus Infection of Natural Killer Cells
}

\author{
Luca D. Bertzbach ${ }^{1}\left(\mathbb{D}\right.$, Daphne A. van Haarlem ${ }^{2}$, Sonja Härtle ${ }^{3} \mathbb{D}$, Benedikt B. Kaufer ${ }^{1, *(\mathbb{D})}$ and \\ Christine A. Jansen ${ }^{2, *}$ \\ 1 Institute of Virology, Freie Universität Berlin, 14163 Berlin, Germany; luca.bertzbach@fu-berlin.de \\ 2 Department of Infectious Diseases and Immunology, Faculty of Veterinary Medicine, Utrecht University, \\ 3584 Utrecht, The Netherlands; d.a.vanhaarlem@uu.nl \\ 3 Department of Veterinary Sciences, Ludwig-Maximilians-Universität München, 80539 Munich, Germany; \\ sonja.haertle@lmu.de \\ * Correspondence: benedikt.kaufer@fu-berlin.de (B.B.K.); c.a.jansen@uu.nl (C.A.J.)
}

Received: 16 October 2019; Accepted: 16 November 2019; Published: 20 November 2019

check for updates

\begin{abstract}
Natural killer (NK) cells are key players in the innate immune response. They kill virus-infected cells and are crucial for the induction of adaptive immune responses. Marek's disease virus (MDV) is a highly contagious alphaherpesvirus that causes deadly T cell lymphomas in chickens. Host resistance to MDV is associated with differences in NK cell responses; however, the exact role of NK cells in the control of MDV remains unknown. In this study, we assessed if MDV can infect NK cells and alter their activation. Surprisingly, we could demonstrate that primary chicken NK cells are very efficiently infected with very virulent RB-1B MDV and the live-attenuated CVI988 vaccine. Flow cytometry analysis revealed that both RB-1B and CVI988 enhance NK cell degranulation and increase interferon gamma (IFN $\gamma$ ) production in vitro. In addition, we could show that the MDV Eco Q-encoded oncogene (meq) contributes to the induction of NK cell activation using meq knockout viruses. Taken together, our data revealed for the first time that NK cells are efficiently infectable with MDV and that this oncogenic alphaherpesvirus enhances NK cell degranulation and increased IFN $\gamma$ production in vitro.
\end{abstract}

Keywords: NK cells; chickens; cell tropism; CD107; interferon gamma (IFN $\gamma$ ); RB-1B; CVI988; meq

\section{Introduction}

Marek's disease virus (MDV) is an alphaherpesvirus that causes deadly lymphomas in chickens with a mortality of up to $100 \%$ [1]. The development of the lymphoproliferative disease is accompanied by clinical signs including immunosuppression, torticollis, ataxia, and paralysis [1]. In infected animals, MDV productively infects chicken B and T cells [2-4] and establishes latency mostly in CD4+ T cells [5]. In addition, it has been recently shown that MDV can also infect certain phagocytes and endothelial cells [6-8]. Upon infection of chickens, MDV activates both innate and adaptive immune responses [9]. One of the cell types involved in the early MDV-specific immune response are natural killer (NK) cells [10].

NK cells are major components of the innate immune system and belong to group I innate lymphocytes. These cells are known to rapidly kill virus-infected cells [11,12] and play a crucial role in tumor immunosurveillance [13]. Activation of NK cells leads to degranulation of cytotoxic granules containing perforin and granzyme and production of various cytokines including interferon gamma (IFN $\gamma)$ [14]. IFN $\gamma$ is involved in activation of the adaptive immune system $[15,16]$ and orchestrates the expression of interferon inducible genes [17]. Interestingly, NK cell responses are thought to be involved in resistance to MDV [18], as NK cell activity is elevated in MDV-resistant chickens when 
compared to susceptible lines [10,19]. Moreover, vaccination against MDV has been shown to enhance NK cell activity, which is associated with a better vaccine protection [20]. Unfortunately, until now very little was known about the interplay of MDV with NK cells and their response to infection. In a previous study, we identified markers that are expressed on chicken NK cells and developed assays to measure NK cell degranulation and killing [21]. Here we used these tools and recombinant viruses to determine if MDV can infect NK cells and if this affects NK cell degranulation and IFN $\gamma$ secretion.

We demonstrate that both a very virulent strain and the CVI988 vaccine strain efficiently infect primary chicken NK cells. In these infected cultures, we observed an increased NK cell degranulation and IFN $\gamma$ production. Moreover, we demonstrate that the increased NK cell degranulation is dependent on the expression of the major MDV oncogene meq [22]. Our study provides the first evidence that NK cells are efficiently infected, highlighting a so far unknown tropism of this highly oncogenic herpesvirus.

\section{Materials and Methods}

\subsection{Cells}

Chicken embryo cells (CEC) were isolated from 11-day-old VALO specific-pathogen-free (SPF) embryos (VALO Biomedia; Osterholz-Scharmbeck, Germany) as described previously [23]. CECs were maintained in minimal essential medium (MEM, PAN Biotech; Aidenbach, Germany) supplemented with $1-10 \%$ fetal bovine serum (PAN Biotech) and $100 \mathrm{U} / \mathrm{ml}$ penicillin and $100 \mu \mathrm{g} / \mathrm{ml}$ streptomycin (AppliChem; Darmstadt, Germany) at $37^{\circ} \mathrm{C}$ and $5 \% \mathrm{CO}_{2}$.

Splenocytes were isolated from 14-day-old Novogen brown embryos, which we obtained from a commercial hatchery (Verbeek; Zeewolde, The Netherlands). At this developmental stage, a population of cells that resemble mammalian NK cells is abundantly present in the embryonic spleen. These cells lack surface expression of T or B cell-specific antigens and are able to kill a NK-susceptible target cell line [24]. We will refer to this population as NK cells. NK cells were maintained in Iscove Modified Dulbecco Medium (IMDM) supplemented with 2\% heat inactivated fetal bovine serum, $8 \%$ heat inactivated chicken serum (Biochrom; Berlin, Germany), $100 \mathrm{U} / \mathrm{ml}$ penicillin, $100 \mu \mathrm{g} / \mathrm{ml}$ streptomycin and $2 \mathrm{mM}$ glutamax I (Gibco; Carlsbad, CA, USA), which we refer to as "NK medium". NK cells were isolated as previously described [21]. Briefly, spleens were homogenized using a $70 \mu \mathrm{M}$ cell strainer (Beckton Dickinson (BD); Franklin Lakes, NJ, USA) to obtain a single cell suspension. Viable cells were then purified by Ficoll-Paque density gradient centrifugation [25], resuspended in NK medium and used directly or stored in liquid nitrogen until further use.

\subsection{Viruses}

MDV reporter viruses expressing the green fluorescent protein (GFP) under the control of the herpes simplex virus 1 (HSV-1) thymidine kinase promotor were generated based on the very virulent RB-1B field strain and the vaccine strain CVI988. GFP was inserted into the bacterial artificial chromosome (BAC) backbone replacing the Escherichia coli gpt gene (Eco-gpt). The RB-1B $\Delta$ meq virus was generated by en-passant mutagenesis (Figure S1) as described previously [26,27] using the primers provided in Table S1. All recombinant GFP reporter viruses were reconstituted by transfection of fresh CEC with purified BAC DNA using $\mathrm{CaPO}_{4}$ transfection [28]. The viruses were propagated on CEC for up to six passages, and infected cells were stored in liquid nitrogen.

\subsection{Growth Kinetics and Plaque Assays}

The replication properties of all recombinant viruses were determined by plaque size assays and quantitative PCR (qPCR)-based multi-step growth kinetics. For plaque size assays, one million CEC were infected with 100 plaque-forming units (PFU) of each virus and MDV plaques were analyzed at 6 days post infection (dpi). Images of at least 50 randomly selected plaques were taken and plaque areas determined using Image J (National Institutes of Health, USA). For multi-step growth kinetics, 6 well plates were infected with 100 PFU of each virus in each well. Every day, one well was harvested, 
and DNA extracted using the Invisorb®DNA Tissue HTS 96 Kit (Stratec Molecular; Berlin, Germany) according to the manufacturer's instructions. MDV genome copies were determined by qPCR as we described previously [4] using the primers and probes provided in Table S1. Growth kinetics and plaque sizes were determined in three independent experiments.

\subsection{Infection of NK Cells}

GFP-expressing RB-1B or CVI988-infected CEC and uninfected CEC (mock) were thawed and seeded into a 24 well cell culture plate with PFUs ranging from $2.5 \times 10^{4}$ to $10^{5}$. In parallel, primary NK cells were labeled with a PKH26 red fluorescent cell linker kit (Sigma-Aldrich; Zwijndrecht, The Netherlands) according to the manufacturer's protocol. $2 \times 10^{5}$ cells $/ \mathrm{ml}$ labeled NK cells were added to the uninfected and infected CEC monolayer. Cultures were incubated at $37^{\circ} \mathrm{C}$ and $5 \% \mathrm{CO}_{2}$ for $4 \mathrm{~h}$ (CD107 surface expression analysis), or $6 \mathrm{~h}$ (analysis of IFN $\gamma$ production). Additionally, co-cultures of GFP-labeled viruses and unlabeled NK cells were performed, which were incubated for up to $72 \mathrm{~h}$ to assess infectivity of these viruses in NK cells.

\subsection{CD107 Assay}

The CD107 assay was used as previously described with some minor modifications [21]. Briefly, Golgistop (BD) was added to the cells in a final dilution of 1:1000, together with an allophycocyanin (APC)-conjugated mouse anti-chicken CD107 monoclonal antibody (mouse anti-chicken LEP-100, I (IgG1), clone 5G10. Developmental Studies Hybridoma Bank (DSHB); University of Iowa, IA, USA). To separate wells containing NK cells in the absence of virus, phorbol-12-myristate 13-acetate (PMA)/ionomycin (Sigma-Aldrich) and medium were added as positive and negative control respectively, as previously described [21]. After co-culturing virus-infected CEC and NK cells for $4 \mathrm{~h}$ at $37^{\circ} \mathrm{C} / 5 \% \mathrm{CO}_{2}$, non-adherent cells were harvested for flow cytometry.

\subsection{IFN $\gamma$ Assay}

To analyze interferon gamma (IFN $\gamma$ ) production by NK cells, Golgiplug (BD) was added to each well of the co-cultures in a final dilution of 1:1000 followed by an incubation of $6 \mathrm{~h}$ at $37^{\circ} \mathrm{C} / 5 \% \mathrm{CO}_{2}$ before non-adherent cells were harvested for flow cytometry.

\subsection{Flow Cytometry}

In experiments with unlabeled NK cells, the non-adherent cells were stained with an APC conjugated mouse-anti-chicken CD45 antibody (LT40, IgM, Southern Biotech; Birmingham, AL, USA) for $20 \mathrm{~min}$ at $4{ }^{\circ} \mathrm{C}$. Next, cells were washed and resuspended in a fluorescence activated cell sorting (FACS) buffer made of PBS supplemented with $0.5 \%$ bovine serum albumin (BSA) and $0.005 \% \mathrm{NaN}_{3}$. For CD107 measurements, the non-adherent cells were washed and resuspended in FACS buffer.

To analyze IFN $\gamma$ by intracellular cytokine staining, the non-adherent cells were washed in FACS buffer and permeabilized for $10 \mathrm{~min}$ with $0.5 \mathrm{~mL}$ of 1 volume of FACS permeabilizing solution (BD), 1 volume of FACS lysing solution (BD), and 8 volumes of water. Next, cells were washed in FACS buffer and stained with an APC-conjugated mouse-IgG1 anti-chicken IFN $\gamma$ antibody (mAb80), kindly provided by Dr. Lowenthal [29]. After a $20 \mathrm{~min}$ incubation at $4{ }^{\circ} \mathrm{C}$, the cells were washed and resuspended in FACS buffer.

At least 50,000 cells in the lymphocyte gate were acquired using a FACS Canto flow cytometer (BD). Data were analyzed with FlowJo (Tree Star Inc.; Ashland, OR, USA). NK cells were selected as either CD45 positive or PKH26 positive cells. Cells that were double positive for CD45 and GFP or PKH26 and GFP were defined as MDV-infected chicken NK cells. 


\subsection{Statistical Analyses}

Non-parametric statistical tests were used when the assumption of normal distributed data were not met. A p-value of $<0.05$ was considered statistically significant. All statistical analyses were performed using the program GraphPad Prism 7.05 (GraphPad Software, Inc.; La Jolla, CA, USA).

\section{Results and Discussion}

\subsection{Reporter Viruses Replicate to Comparable Levels}

To assess the ability of MDV to infect NK cells, we used GFP expressing reporter viruses. To confirm that the reporter viruses replicate in a comparable manner, we performed plaque size assays and multi-step growth kinetics as described above. Plaque size assays revealed that all reporter viruses efficiently replicate at comparable levels. (Figure 1A, Figure S2). We confirmed these results using qPCR-based multi-step growth kinetics (Figure 1B). These results are in line with the replication of previously generated reporter viruses [30,31].

\section{A}

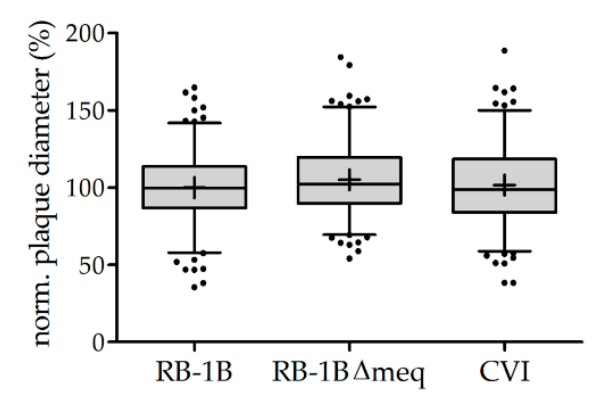

C

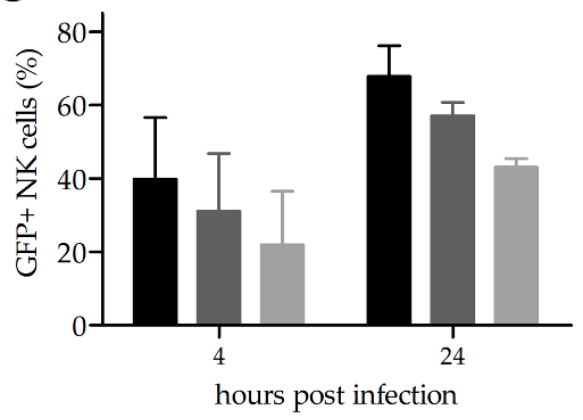

B
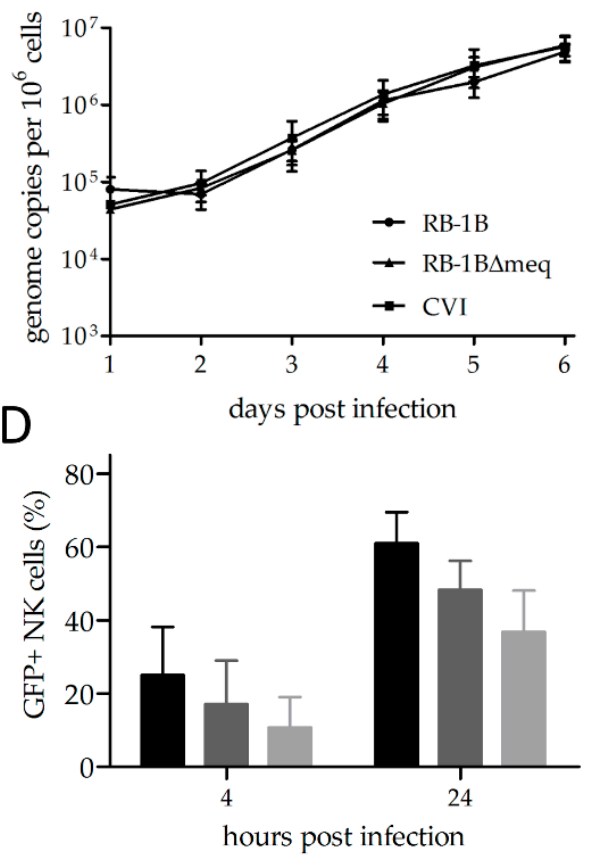

Figure 1. Virus in vitro characterization and natural killer (NK) cell infection rates. (A) Plaque size assays and (B) multi-step growth kinetics of indicated viruses ( $p>0.05$, one-way analysis of variance (ANOVA)). (C) NK-cell infection rates upon infection with the very virulent RB-1B strain and (D) the Marek's disease virus (MDV) vaccine strain CVI988 at 4 and $24 \mathrm{~h}$ post infection with different plaque forming units (PFU): black $=10^{5} \mathrm{PFU}$, dark gray $=5 \times 10^{4} \mathrm{PFU}$, light gray $=2.5 \times 10^{4} \mathrm{PFU}$. Error bars represent the standard error of the mean.

\subsection{Can Readily Infect Chicken NK Cells}

Next, we assessed the ability of RB-1B and the CVI988 vaccine to infect primary NK cells by co-cultivation with infected CEC. To our surprise, we could very efficiently infect chicken NK cells at levels between 20 and 75 percent depending on the dose of infection after 4 and $24 \mathrm{~h}$ post infection (Figure 1C,D). The rate of infection was thereby dependent on the PFU present in the inoculum. Higher infection rates were observed for RB-1B (Figure 1C) when compared to CVI988 (Figure 1D), indicating that a virulent virus infects NK cells more efficiently. 
These infection rates were higher than observed in primary B and T cells [32], in primary endothelial cells [8], and in primary macrophages [7]. In those cells, infection rates ranged from $2-20 \%$. Notably, we optimized the B cell infection system since it was published [32] and readily achieve infection rates of about $50 \%$ in primary chicken B cells in vitro.

\subsection{Enhances NK Cell Degranulation and Increases IFN $\gamma$ Production}

To investigate the effect of MDV on NK cell activation, we performed co-cultures of MDV and primary NK cells and analyzed NK cell activation by measuring CD107 surface expression as a proxy for degranulation and the production of interferon gamma (IFN $\gamma$ ) by flow cytometry. Prior to co-cultivation, NK cells were labeled with the fluorescent dye PKH26 to allow efficient discrimination between NK cells and infected CEC. PKH26 positive cells were selected within the single cell population. It is important to note that CD3 is not expressed in these cells as described previously [21]. Based on forward and side scatter, we selected the lymphocyte population and assessed the CD107 surface expression. Next, we analyzed the GFP expression within the CD107 positive cells by gating on the GFP positive or GFP negative cells (Figure 2).

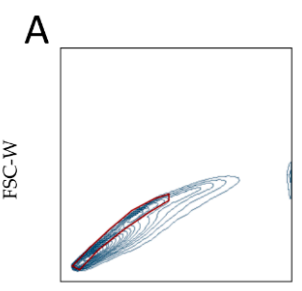

FSC-A

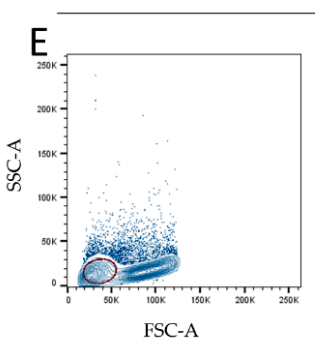

FSC-A

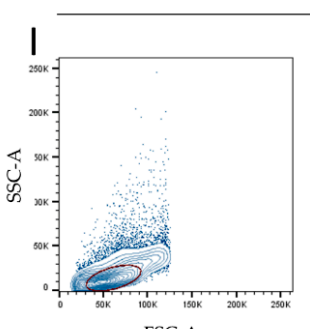

FSC-A

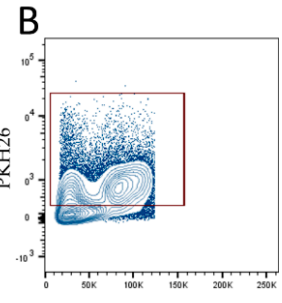

FSC-A

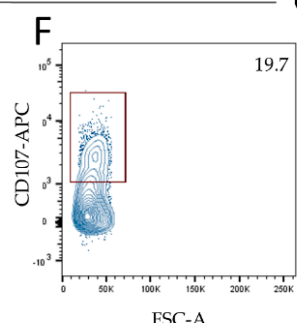

FSC-A

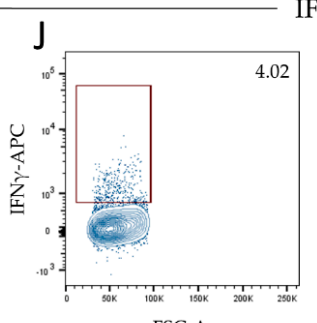

FSC-A

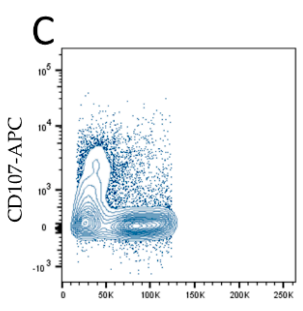

FSC-A

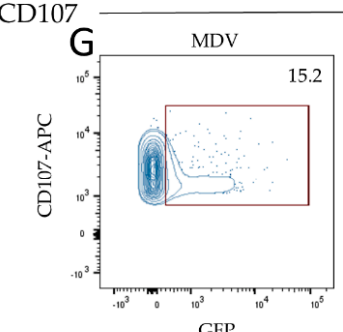

GFP

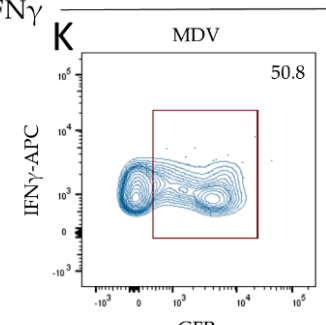

GFP

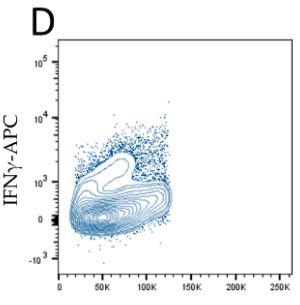

FSC-A

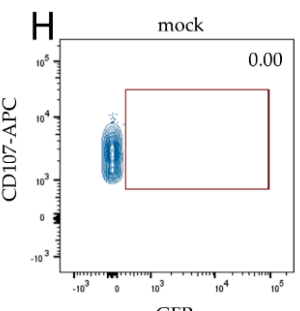

GFP

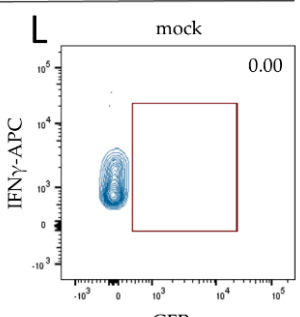

GFP

Figure 2. Gating strategy to determine CD107 positive and interferon gamma (IFN $\gamma$ ) positive NK cells. (A) We gated single cells based on forward scatter-area (FSC-A) and forward scatter-width (FSC-W). (B) Within the single cells, PKH26 labeled NK cells were gated for the subsequent analysis of CD107 expression (D-G) and IFN $\gamma$ expression (H-K). (C) We found that CD107 was expressed on cells with a low forward scatter. (D) IFN $\gamma$ plotted against FSC-A scatter showed one population of cells that expressed IFN $\gamma$. (E) Lymphocytes were gated based on forward and side scatter. (F) Within this gate, we selected the CD107 positive cells and determined GFP positive cells in (G) MDV-infected and (H) mock-infected cultures. (I) Lymphocytes were gated based on FSC-A and side scatter-area (SSC-A). (J) We then selected the IFN $\gamma$ producing cells within the lymphocyte gate and subsequently determined GFP positive cells in (K) MDV-infected and (L) mock-infected cultures. 
When NK cells were incubated with 100,000 PFU of the virulent strain RB-1B, CD107 expression increased from $1.56 \%$ to $3.51 \%$ compared to the mock $(p>0.05)$. A similar trend was observed in a co-culture of NK cells with CVI988 (Figure 3A). Furthermore, we investigated if MDV infections induce IFN $\gamma$ production by intracellular cytokine staining, since the expression of CD107 is known to correlate with IFN $\gamma$ production [21]. Again, single cells were gated and within that population, we selected the PKH26 positive NK cells. We could readily detect a population of IFN $\gamma$ positive cells (Figure 2D) and determine the amount of IFN $\gamma$ positive lymphocytes (Figure 2J) as well as the GFP expression within the IFN $\gamma$ positive cells (Figure 2K). Here, the production of IFN $\gamma$ significantly increased upon co-cultures with RB-1B and CVI988 compared to mock (Figure 3B). Taken together, we could demonstrate that RB-1B and CVI988-infected NK cells show higher levels of surface CD107 and an increased IFN $\gamma$ production when compared to mock-infected cells (Figure 3A,B). Overall, this suggests that NK cells are activated in these cultures. Interestingly, we observed that only the small population of CD107+ cells was infected with MDV, suggesting that the infection could be a consequence of NK cell activation. The same is true for T cell infections by the virus, as it is known that activation is a crucial step for MDV infection of primary chicken T cells [33].
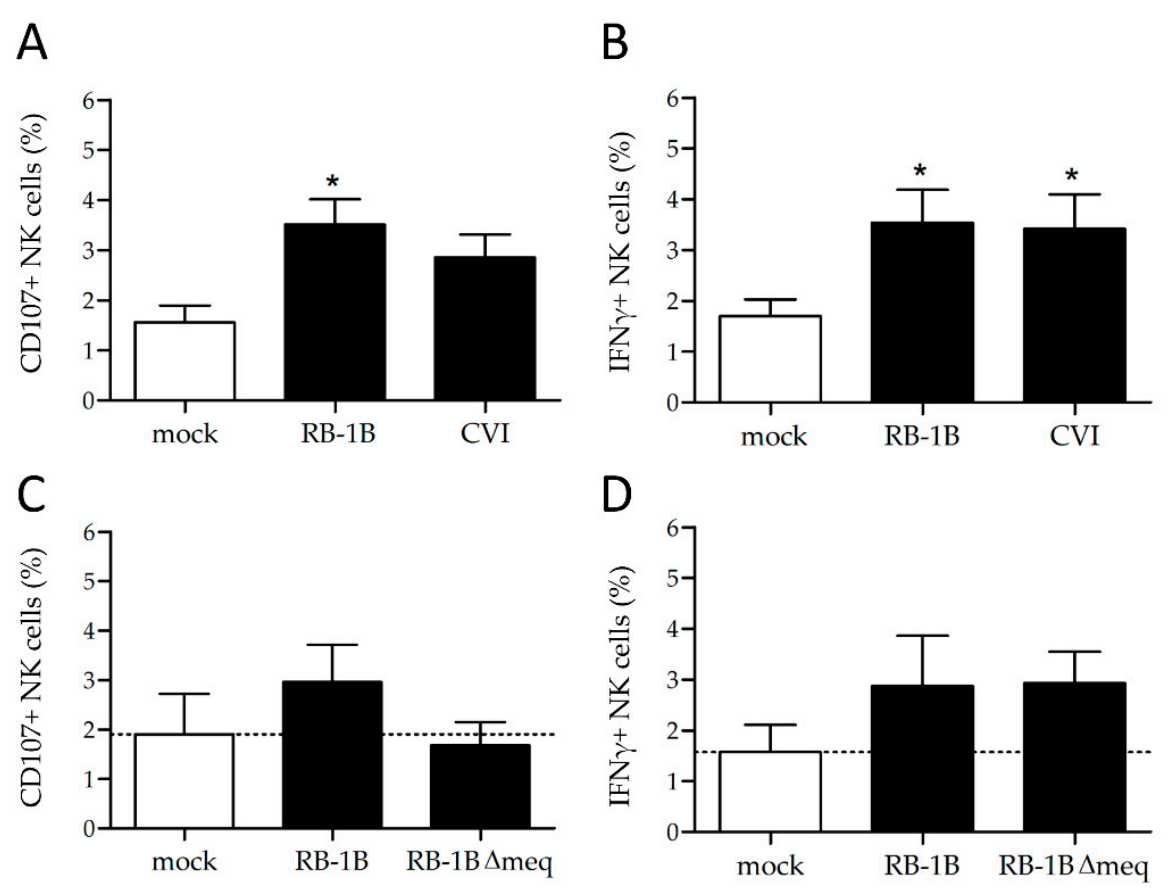

Figure 3. NK cell activation rates and IFN $\gamma$ production. (A) Assessment of CD107+ cells and (B) IFN $\gamma$ production upon infection of NK cells with RB-1B vs CVI988. The same assays were performed to determine differences in (C) the percentage of CD107+ cells and (D) IFN $\gamma$ production comparing infections of NK cells with RB-1B and the RB-1B $\Delta$ meq mutant. Asterisks indicate statistically significant differences to mock-infected cells $\left({ }^{*} p>0.05\right.$, Kruskal-Wallis test). Error bars represent the standard error of the mean.

\subsection{Lower Rates of Activation in the Absence of the Major MDV Oncogene meq}

Finally, to provide a possible mechanistic explanation for the enhanced NK cell activation, we investigated the role of the major MDV oncogene meq on CD107 expression and IFN $\gamma$ production. meq has a plethora of functions including up and downregulation of cellular and viral genes and impacts a variety of disease-associated pathways; however, its full functional significance is not yet completely understood, despite being the most studied MDV gene [34,35].

To assess the role of meq in the NK cell activation, we used a recombinant virus with a deletion of the meq gene. We could demonstrate that the CD107 surface expression on chicken NK cells is comparable to the mock-infected cells upon infection with the meq deletion mutant, while RB-1B and 
CVI988 that express meq induced CD107 (Figure 3C). Interestingly, the levels of IFN $\gamma$ production were not affected in the absence of meq (Figure 3D).

Although both degranulation and IFN $\gamma$ production can be induced upon NK cell activation, these functions are not necessarily executed by one NK cell subset. Different NK cell subsets have been described in humans and mice, based on marker expression and function $[15,36]$. In chickens however, characterization of NK cells subsets is still in its infancy [37]. Differential effects of MDV wild type and mutant viruses on various NK cell subsets could be a likely explanation for the observed effect of the meq deletion mutant.

Our data suggests that meq influences NK cell activation and thereby adds another piece to the puzzle of the wide range of functions of this virulence factor.

\section{Conclusions}

Taken together, we demonstrated that chicken NK cells can be efficiently infected with MDV and thereby shed light on an extended host cell tropism for the virus. Furthermore, our in vitro data demonstrate enhanced NK cell degranulation and release of IFN $\gamma$, which could be part of their antiviral response to MDV infections. Future studies will address the role of NK cells in MDV infection in vivo using NK cell knockout chickens that are hopefully available in the years to come [38].

Supplementary Materials: The following are available online at http://www.mdpi.com/2076-2607/7/12/588/s1, Figure S1: Generation of recombinant viruses, Figure S2: Representative plaque images, Table S1: Primers and TaqMan probes used in this study.

Author Contributions: Conceptualization L.D.B., B.B.K. and C.A.J.; methodology, L.D.B., D.A.v.H., S.H., B.B.K. and C.A.J.; formal analysis, L.D.B., D.A.v.H. and C.A.J.; investigation, L.D.B., D.A.v.H. and C.A.J.; writing—original draft preparation, L.D.B., B.B.K. and C.A.J.; writing-review and editing, L.D.B., D.A.v.H., S.H., B.B.K. and C.A.J.; visualization, L.D.B. and C.A.J.; supervision, B.B.K. and C.A.J.; project administration, B.B.K. and C.A.J.; funding acquisition, S.H., B.B.K. and C.A.J.

Funding: This research was funded by the Animal Health and Welfare ERA-Net MADISUP project awarded to S.H., B.B.K. and C.A.J and the Volkswagen Foundation Lichtenberg grant A112662 awarded to B.B.K.

Acknowledgments: The authors cordially thank Ann Reum for excellent technical assistance. The publication of this article was funded by Freie Universität Berlin.

Conflicts of Interest: The authors declare no conflict of interest.

\section{References}

1. Schat, K.A.; Nair, V. Neoplastic Diseases. In Diseases of Poultry; Swayne, D.E., Ed.; John Wiley \& Sons; Inc.: Hoboken, NJ, USA, 2017; pp. 513-673.

2. Baigent, S.J.; Ross, L.J.; Davison, T.F. A flow cytometric method for identifying Marek's disease virus pp38 expression in lymphocyte subpopulations. Avian Pathol. 1996, 25, 255-267. [CrossRef]

3. Baaten, B.J.; Staines, K.A.; Smith, L.P.; Skinner, H.; Davison, T.F.; Butter, C. Early replication in pulmonary B cells after infection with Marek's disease herpesvirus by the respiratory route. Viral Immunol. 2009, 22, 431-444. [CrossRef] [PubMed]

4. Bertzbach, L.D.; Laparidou, M.; Hartle, S.; Etches, R.J.; Kaspers, B.; Schusser, B.; Kaufer, B.B. Unraveling the role of B cells in the pathogenesis of an oncogenic avian herpesvirus. Proc. Natl. Acad. Sci. USA 2018, 115, 11603-11607. [CrossRef] [PubMed]

5. Morgan, R.W.; Xie, Q.; Cantello, J.L.; Miles, A.M.; Bernberg, E.L.; Kent, J.; Anderson, A. Marek's disease virus latency. Curr. Top. Microbiol. Immunol. 2001, 255, 223-243. [PubMed]

6. Barrow, A.D.; Burgess, S.C.; Baigent, S.J.; Howes, K.; Nair, V.K. Infection of macrophages by a lymphotropic herpesvirus: A new tropism for Marek's disease virus. J. Gen. Virol. 2003, 84, 2635-2645. [CrossRef]

7. Chakraborty, P.; Vervelde, L.; Dalziel, R.G.; Wasson, P.S.; Nair, V.; Dutia, B.M.; Kaiser, P. Marek's disease virus infection of phagocytes: A de novo in vitro infection model. J. Gen. Virol. 2017, 98, 1080-1088. [CrossRef]

8. Lion, A.; Esnault, E.; Kut, E.; Guillory, V.; Trapp-Fragnet, L.; Soubies, S.M.; Chanteloup, N.; Niepceron, A.; Guabiraba, R.; Marc, D.; et al. Chicken endothelial cells are highly responsive to viral innate immune stimuli and are susceptible to infections with various avian pathogens. Avian Pathol. 2018, 48,1-41. [CrossRef] 
9. Haq, K.; Schat, K.A.; Sharif, S. Immunity to Marek's disease: Where are we now? Dev. Comp. Immunol. 2013, 41, 439-446. [CrossRef]

10. Sharma, J.M. Natural killer cell activity in chickens exposed to Marek's disease virus: Inhibition of activity in susceptible chickens and enhancement of activity in resistant and vaccinated chickens. Avian Dis. 1981, 25, 882-893. [CrossRef]

11. Newman, K.C.; Riley, E.M. Whatever turns you on: Accessory-cell-dependent activation of NK cells by pathogens. Nat. Rev. Immunol. 2007, 7, 279-291. [CrossRef]

12. Jost, S.; Altfeld, M. Control of human viral infections by natural killer cells. Annu. Rev. Immunol. 2013, 31, 163-194. [CrossRef] [PubMed]

13. Bruchard, M.; Ghiringhelli, F. Deciphering the Roles of Innate Lymphoid Cells in Cancer. Front. Immunol. 2019, 10, 656. [CrossRef] [PubMed]

14. Voskoboinik, I.; Whisstock, J.C.; Trapani, J.A. Perforin and granzymes: Function, dysfunction and human pathology. Nat. Rev. Immunol. 2015, 15, 388-400. [CrossRef] [PubMed]

15. Cooper, M.; Fehniger, T.A.; Fuchs, A.; Colonna, M.; Caligiuri, M.A. NK cell and DC interactions. Trends Immunol. 2004, 25, 47-52. [CrossRef]

16. Nandakumar, S.; Woolard, S.N.; Yuan, D.; Rouse, B.T.; Kumaraguru, U. Natural killer cells as novel helpers in anti-herpes simplex virus immune response. J. Virol. 2008, 82, 10820-10831. [CrossRef]

17. Schroder, K.; Hertzog, P.J.; Ravasi, T.; Hume, D.A. Interferon-gamma: An overview of signals, mechanisms and functions. J. Leukoc. Biol. 2004, 75, 163-189. [CrossRef]

18. Quere, P.; Dambrine, G. Development of anti-tumoral cell-mediated cytotoxicity during the course of Marek's disease in chickens. Ann. Rech. Vet. 1988, 19, 193-201.

19. Garcia-Camacho, L.; Schat, K.A.; Brooks, R.; Bounous, D.I. Early cell-mediated immune responses to Marek's disease virus in two chicken lines with defined major histocompatibility complex antigens. Vet. Immunol. Immunop. 2003, 95, 145-153. [CrossRef]

20. Heller, E.D.; Schat, K.A. Enhancement of natural killer cell activity by Marek's disease vaccines. Avian Pathol. 1987, 16, 51-60. [CrossRef]

21. Jansen, C.A.; van de Haar, P.M.; van Haarlem, D.; van Kooten, P.; de Wit, S.; van Eden, W.; Viertlbock, B.C.; Gobel, T.W.; Vervelde, L. Identification of new populations of chicken natural killer (NK) cells. Dev. Comp. Immunol. 2010, 34, 759-767. [CrossRef]

22. Lupiani, B.; Lee, L.F.; Cui, X.; Gimeno, I.; Anderson, A.; Morgan, R.W.; Silva, R.F.; Witter, R.L.; Kung, H.J.; Reddy, S.M. Marek's disease virus-encoded Meq gene is involved in transformation of lymphocytes but is dispensable for replication. Proc. Natl. Acad. Sci. USA 2004, 101, 11815-11820. [CrossRef] [PubMed]

23. Schat, K.; Purchase, H. Cell-culture Methods. In A Laboratory Manual for the Isolation and Identification of Avian Pathogens, 4th ed.; American Association of Avian Pathologists: Kennett Square, PA, USA, 1998.

24. Gobel, T.W.; Chen, C.L.; Shrimpf, J.; Grossi, C.E.; Bernot, A.; Bucy, R.P.; Auffray, C.; Cooper, M.D. Characterization of avian natural killer cells and their intracellular CD3 protein complex. Eur. J. Immunol. 1994, 24, 1685-1691. [CrossRef] [PubMed]

25. Bertzbach, L.D.; Pfaff, F.; Pauker, V.I.; Kheimar, A.M.; Höper, D.; Härtle, S.; Karger, A.; Kaufer, B.B. The Transcriptional Landscape of Marek's Disease Virus in Primary Chicken B Cells Reveals Novel Splice Variants and Genes. Viruses 2019, 11, 264. [CrossRef] [PubMed]

26. Conradie, A.M.; Bertzbach, L.D.; Bhandari, N.; Parcells, M.; Kaufer, B.B. A Common Live-Attenuated Avian Herpesvirus Vaccine Expresses a Very Potent Oncogene. mSphere 2019, 4, e00658-19. [CrossRef]

27. Engel, A.T.; Selvaraj, R.K.; Kamil, J.P.; Osterrieder, N.; Kaufer, B.B. Marek's disease viral interleukin-8 promotes lymphoma formation through targeted recruitment of B cells and CD4+ CD25+ T cells. J. Virol. 2012, 86, 8536-8545. [CrossRef]

28. Schumacher, D.; Tischer, B.K.; Fuchs, W.; Osterrieder, N. Reconstitution of Marek's disease virus serotype 1 (MDV-1) from DNA cloned as a bacterial artificial chromosome and characterization of a glycoprotein B-negative MDV-1 mutant. J. Virol. 2000, 74, 11088-11098. [CrossRef]

29. Ariaans, M.P.; van de Haar, P.M.; Lowenthal, J.W.; van Eden, W.; Hensen, E.J.; Vervelde, L. ELISPOT and intracellular cytokine staining: Novel assays for quantifying $\mathrm{T}$ cell responses in the chicken. Dev. Comp. Immunol. 2008, 32, 1398-1404. [CrossRef]

30. Tai, S.S.; Hearn, C.; Umthong, S.; Agafitei, O.; Cheng, H.H.; Dunn, J.R.; Niikura, M. Expression of Marek's Disease Virus Oncoprotein Meq During Infection in the Natural Host. Virology 2017, 503, 103-113. [CrossRef] 
31. Petherbridge, L.; Howes, K.; Baigent, S.J.; Sacco, M.A.; Evans, S.; Osterrieder, N.; Nair, V. Replication-competent bacterial artificial chromosomes of Marek's disease virus: Novel tools for generation of molecularly defined herpesvirus vaccines. J. Virol. 2003, 77, 8712-8718. [CrossRef]

32. Schermuly, J.; Greco, A.; Hartle, S.; Osterrieder, N.; Kaufer, B.B.; Kaspers, B. In vitro model for lytic replication, latency, and transformation of an oncogenic alphaherpesvirus. Proc. Natl. Acad. Sci. USA 2015, 112, 7279-7284. [CrossRef]

33. Schat, K.A.; Markowski-Grimsrud, C.J. Immune responses to Marek's disease virus infection. Curr. Top. Microbiol. Immunol. 2001, 255, 91-120. [PubMed]

34. Bertzbach, L.D.; Kheimar, A.; Ali, F.A.Z.; Kaufer, B.B. Viral Factors Involved in Marek's Disease Virus (MDV) Pathogenesis. Curr. Clin. Microbiol. Rep. 2018, 5, 238-244. [CrossRef]

35. Osterrieder, N.; Kamil, J.P.; Schumacher, D.; Tischer, B.K.; Trapp, S. Marek's disease virus: From miasma to model. Nat. Rev. Microbiol. 2006, 4, 283-294. [CrossRef] [PubMed]

36. Hayakawa, Y.; Smyth, M.J. CD27 dissects mature NK cells into two subsets with distinct responsiveness and migratory capacity. J. Immunol. 2006, 176, 1517-1524. [CrossRef] [PubMed]

37. Jansen, C.A.; de Geus, E.D.; van Haarlem, D.A.; van de Haar, P.M.; Londt, B.Z.; Graham, S.P.; Gobel, T.W.; van Eden, W.; Brookes, S.M.; Vervelde, L. Differential lung NK cell responses in avian influenza virus infected chickens correlate with pathogenicity. Sci. Rep. 2013, 3, 2478. [CrossRef] [PubMed]

38. Sid, H.; Schusser, B. Applications of Gene Editing in Chickens: A New Era Is on the Horizon. Front. Genet. 2018, 9, 456. [CrossRef]

(C) 2019 by the authors. Licensee MDPI, Basel, Switzerland. This article is an open access article distributed under the terms and conditions of the Creative Commons Attribution (CC BY) license (http://creativecommons.org/licenses/by/4.0/). 